\title{
Segmentation of Optical Remote Sensing Images for Detecting Homogeneous Regions in Space and Time
}

Segmentação de imagens ópticas de sensoriamento remoto para detecção de regiões homogêneas no espaço e no tempo

\author{
Wanderson Santos Costa ${ }^{1}$, Leila Maria Garcia Fonseca ${ }^{1}$, Thales Sehn \\ Körting ${ }^{1}$, Margareth Simões ${ }^{2}$, Hugo do Nascimento Bendini ${ }^{1}$ \& Ricardo \\ Cartaxo Modesto Souza ${ }^{1}$
}

Recebido em abril de 2018. Aprovado em novembro de 2018.

\begin{abstract}
With the amount of multitemporal and multiresolution images growing exponentially, the number of image segmentation applications is recently increasing and, simultaneously, new challenges arise. Hence, there is a need to explore new segmentation concepts and techniques that make use of the data temporality. This study describes a spatio-temporal segmentation that adapts the traditional region growing technique to detect homogeneous regions in space and time in optical remote sensing images. Tests were conducted by considering the Dynamic Time Warping measure as the homogeneity criterion. Study cases on high temporal resolution for sequences of MODIS and Landsat-8 OLI vegetation indices products and comparisons with other distance measurements provided satisfactory outcomes.
\end{abstract}

KEYWORDS: Spatio-temporal segmentation. Image Processing. Dynamic Time Warping.

\section{RESUMO}

Com o aumento exponencial do volume de imagens multitemporais e de multirresolução, a quantidade de aplicações que envolvem técnicas de segmentação está continuamente crescendo e, simultaneamente, novos desafios surgem. Com isso, há a necessidade de elaborar novos conceitos e técnicas de segmentação que explorem a temporalidade dos dados. Este estudo descreve uma técnica de segmentação espaço-temporal que adapta o método tradicional de crescimento de regiões com o objetivo de detectar regiões homogêneas no espaço e no tempo em imagens ópticas de

\footnotetext{
${ }^{1}$ Instituto Nacional de Pesquisas Espaciais. Divisão de Processamento de Imagens. São José dos Campos - SP - Brazil.

E-mail: \{wanderson.costa, leila.fonseca, thales.korting, hugo.bendini\}@inpe.br, cartaxo@dpi.inpe.br .

2 Embrapa Solos. Rio de Janeiro - RJ - Brazil.

E-mail: margareth.simoes@embrapa.br
} 
sensoriamento remoto. Testes foram conduzidos considerando a distância Dynamic Time Warping como critério de homogeneidade. Estudos de caso foram realizados com produtos com alta resolução temporal de sequências de imagens de índices de vegetação dos sensores MODIS e Landsat-8 OLI e a comparação com outras medidas de distância forneceram resultados qualitativos satisfatórios.

PALAVRAS-CHAVE: Segmentação espaço-temporal. Processamento de imagens. Dynamic Time Warping.

\section{Introduction}

Satellite image analysis is a key role for detecting land use/cover changes in different biomes. The extensive amount of remote sensing data, combined with information from ecosystem models, offers a good opportunity for predicting and understanding the behavior of terrestrial ecosystems (BORIAH, 2010). As satellite products have a repetitive data acquisition and its digital format is suitable for computer processing, remote sensing data have become the main source for application of change detection and observation of land use and land cover during the last decades (LAMBIN and LINDERMAN, 2006).

If the image analysis is performed using only pixelwise techniques, inherent information of the objects in the scene are discarded, such as shape, area and statistical parameters. In order to exploit this information, there are segmentation algorithms, which partition images into regions whose pixels present similar properties (BLASCHKE, 2010; BINS et al., 1996). Using a homogeneity criterion between the image pixels, the identified segments are treated as regions from which features can be extracted to be used in the image analysis. Consequently, the result of segmentation process reduces the volume of data to be studied in the analysis, regarding the number of elements to be analyzed.

Several segmentation techniques applied in change detection are still derived from the traditional snapshot model (DEY et al., 2010), that analyzes 
each time step independently. However, a thorough literature review revealed a record of few studies that adapted methods based on objects for applications with multitemporal data (THOMPSON and LEES, 2014).

Change detection based on time series is advantageous compared to the pure observation of image sequences, since the series takes into account information regarding temporal dynamics and changes in the landscape rather than just observing the differences between two or more images collected on different dates (BORIAH, 2010). Continuous observations from remote sensors provide high temporal and spatial resolution imagery, and better remote sensing image segmentation techniques are mandatory for efficient analysis (SCHIEWE, 2002; DEY et al., 2010). Nonetheless, a large amount of temporal data has been generated over the past years, which forces the remote sensing community to rethink processing strategies for satellite time series analysis and visualization (FREITAS et al., 2011).

In this paper, we describe a segmentation method applied to time series of Earth Observation data. The method integrates regions in order to detect objects that are homogeneous in space and time. This approach aims to overcome the limitations of the snapshot model, adapting the well-known segmentation method based on spatial region growing (ADAMS and BISCHOF, 1994). Study cases were conducted using time series of MODIS and Landsat-8 OLI scenes by applying spatio-temporal segmentation using the Dynamic Time Warping measure (SAKOE and CHIBA, 1971) as the homogeneity criterion.

This paper is an extended version of Costa et al., (2017), presented in XVIII Brazilian Symposium on GeoInformatics (GEOINFO 2017).

\section{Remote Sensing Image Segmentation}

One of the first steps in every remote sensing image analysis, segmentation is a basic and critical task in image processing whereby the image is partitioned into regions, also called objects, whose pixels are similar 
considering one or more properties (HARALICK and SHAPIRO, 1985). Overall, it is expected that the objects of interest are automatically extracted as a result of segmentation. Features can be extracted from these objects and used later for data analysis.

However, segmentation algorithms generally do not yield a perfect partition of the scene, producing segments that divide the targets of interest into several regions (over-segmentation) or generate regions containing more than one target (under-segmentation). By applying segmentation methods for remote sensing data, both aforementioned results may happen within a single scene, depending on the heterogeneity of the objects that are taken into account (SCHIEWE, 2002). In addition, many segmentation algorithms are directed to a simplified class of problems or data. Errors and distortions in the segmentation process are reflected in the subsequent steps, including classification.

The region growing algorithm (ADAMS and BISCHOF, 1994) is one of the most applied segmentation techniques in remote sensing image processing. The method groups pixels or sub-regions into larger regions depending on how they are similar or not, using some similarity criteria. The technique starts with a set of pixels called seeds and, from them, grows regions by adding neighbor pixels with similar properties.

Parameters tuning and threshold definitions in region growing segmentation are key steps due to their direct influence on the accuracy of the output. For example, if the difference between the seed pixel and its neighbor pixel values is less than a given threshold (usually defined as similarity threshold), the neighbor pixel is considered similar and it is added to a region. This value supports the user to control the segmentation result in an interactive way, depending on the goal and study area (OLIVEIRA, 2002).

Furthermore, it is reported that there is not an optimal parameters tuning, since it depends on the image type, land cover, the period in which the data was collected and research purposes. For instance, the similarity threshold is reached after several tests among possible combinations of the 
algorithm. The tests continue until the result of the segmentation is suitable for a particular purpose (OLIVEIRA, 2002).

Many of the recent segmentation processes have paid attention to high image spatial resolutions whereas, so far, there are few studies adapted to multitemporal data (THOMPSON and LEES, 2014). Most of the change detection analysis uses the well-known snapshot model (HARALICK and SHAPIRO, 1985), observing only the differences between discrete dates (DEY et al., 2010; DURO et al., 2013; GÓMEZ et al., 2011). Additionally, most of the multitemporal analysis performs inferences about the nature of the changes after the image processing, that is, the understanding of the phenomenon changes is inferred by measuring the number and the magnitude of the observed differences in the objects after the change.

Some change detection techniques aim at performing the segmentation generating one output for each instant of time and then comparing the region changes over time (IM et al., 2008; NIEMEYER et al., 2008; GÓMEZ et al., 2011). In other studies, the objects are defined in the first image, and then their differences are analyzed in subsequent image (BLASCHKE, 2005; PAPE and FRANKLIN, 2008; DURO et al., 2013).

Another approach has included the time as an additional factor within the segmentation, being used with the spatial and spectral image features (THOMPSON and LEES, 2014). However, many studies that apply this segmentation approach have used a limited number of multitemporal images (BONTEMPS et al., 2008; DESCLÉE et al., 2006; DRĂGUȚ et al., 2010; DRĂGUȚ et al., 2014) and they did not make use of time series of high temporal resolution images (DEY et al., 2010). A direct characterization of changes in a phenomenon requires that the observations are done during the change process (THOMPSON and LEES, 2014), which can be exploited through high temporal resolution images. 


\section{Satellite Image Time Series}

Satellite image time series (SITS) offer new perspectives for the understanding of ocean, land and atmospheric changes by identifying the factors that cause these modifications and predicting future changes (BORIAH, 2010). The time component, integrated with spatial and spectral properties of the images, can result in a rich source of information that, if properly explored, reveals complex and important patterns found on the environment, including the land and ocean dynamics (BRUZZONE, SMITS and TILTON et al., 2003).

Sensors such MODIS (Moderate Resolution Imaging Spectroradiometer) aboard the Terra (EOS-AM1) and Acqua (EOS-PM1) satellites, and Landsat-8 OLI (Operational Land Imager) from Landsat program have been responsible for the generation of large time series datasets. These sensors acquire images in regular and short intervals, which is an important feature to analyze changes in land use and land cover. Products extracted from the MODIS sensor and the Landsat program represent two of the most commonly used datasets to generate time series in change detection studies (GÓMEZ et al., 2011).

The satellites from program Landsat have collected images since 1972 (COHEN and GOWARD, 2004). Currently, Landsat-7 and Landsat-8 OLI are active, generating images with temporal resolution of 16 days and spatial resolution of $30 \mathrm{~m}$. The MODIS sensor can provide images with daily intervals, although the spatial resolution of its products varies from $250 \mathrm{~m}$ to $1 \mathrm{~km}$.

SITS are relevant data in the study of dynamic phenomena and the interpretation of their evolution over time (BOULILA et al., 2011). The time series of vegetation indices, for example, can be used to analyze seasonality for cover monitoring purposes. Vegetation indices represent improved measures of spatial, spectral and radiometric surface vegetation conditions (TUCKER et al., 2005). In the analysis and characterization of vegetation 
cover, for example, vegetation indices are used for seasonal and inter-annual monitoring of biophysical, phenological and structural vegetation parameters (HUETE et al., 2002). Figure 1 shows the time series generation for a pixel $p(x, y)$. For each pixel, a time series can be observed, representing the pixel value variation over time.

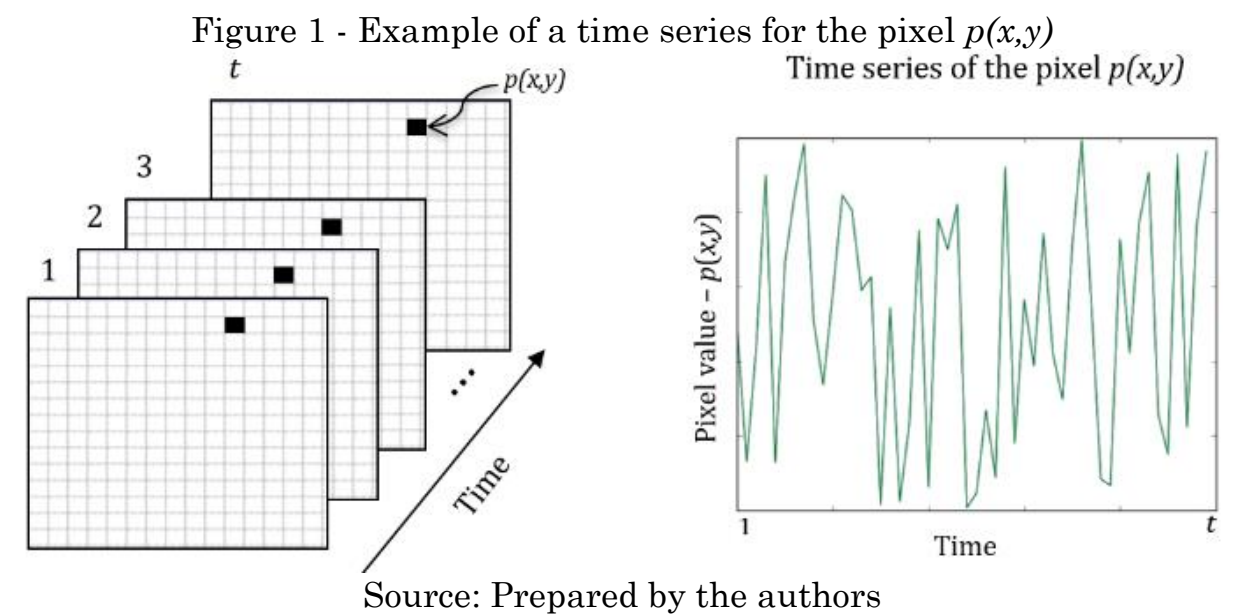

One of most used vegetation indices is the NDVI (Normalized Difference Vegetation Index) (JUSTICE et al., 2002) and its calculation is based on the reflectance of red and near-infrared wavelengths (TUCKER, 1979). The band ratio in the calculation of NDVI reduces some forms of noise, such as the lighting differences, cloud shadows and topographical variations. However, this index has low sensitivity in regions with high concentration of biomass and may have limitations related to soil brightness variations (JIANG et al., 2008).

\section{Dynamic Time Warping}

Dynamic Time Warping (DTW) is one of the most used measures to quantify the similarity between two time series (PETITJEAN et al., 2012). Originally designed to treat automatic speech recognition (SAKOE and 
CHIBA, 1971; SAKOE and CHIBA, 1978), DTW measures the optimal global alignment between two time series and exploits temporal distortions.

The choice for a good similarity measure plays a key role since it defines the way to treat the temporality of data. The main change detection analysis in remote sensing images consists in comparing the data to estimate the similarity between them (PETITJEAN et al., 2011). In many cases, the similarity is computed using a distance measure observing two instances.

Among the known distances, DTW has the ability to realign two time series, so that each element of the first series is associated with at least one of the second series. With DTW, two time series out of phase can be aligned in a nonlinear form (Figure 2). Providing the cost of this alignment, DTW highlights similarities that the Euclidean distance is not able to capture, comparing shifted or distorted time series (PETITJEAN et al., 2011).

Figure 2 - Although the two series have similar shapes, they are not aligned in the time axis. DTW nonlinear alignment allows a more intuitive distance to be calculated.
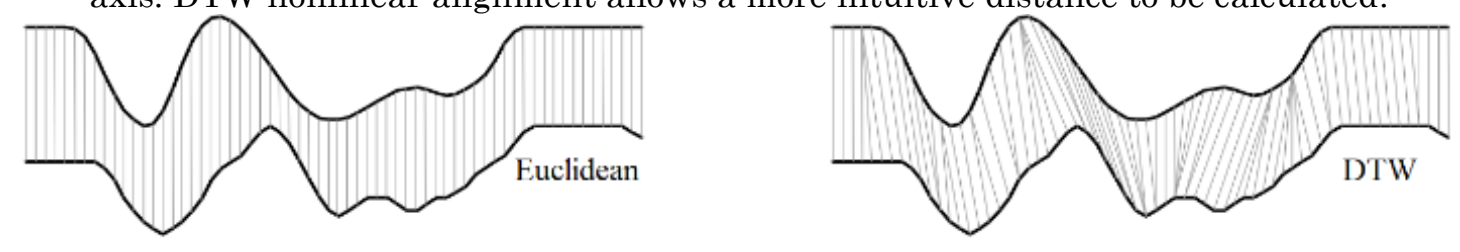

Source: Adapted from Chu et al. (2002).

Let $A$ and $B$ be two time series of length $M$ and $N$, respectively, where $A=\left(a_{1}, a_{2}, \ldots, a_{M}\right)$ and $B=\left(b_{1}, b_{2}, \ldots, b_{N}\right)$. The first step for calculating the DTW measure between $A$ and $B$ is to build a matrix of size $M \times N$, where each matrix element $(i, j)$ corresponds to a distance measured between $a_{i}$ and $b_{j}$. This distance, $\delta\left(a_{i}, b_{j}\right)$ can be computed using different metrics, such as the Manhattan distance $d\left(a_{i}, b_{j}\right)=\left|a_{i}-b_{j}\right|$ or the Euclidean distance. The matrix can be recursively calculated by (Equation 1 ): 


$$
D\left(a_{i}, b_{j}\right)=\delta\left(a_{i}, b_{j}\right)+\min \left\{\begin{array}{c}
D\left(a_{i-1}, b_{j-1}\right) \\
D\left(a_{i}, b_{j-1}\right) \\
D\left(a_{i-1}, b_{j}\right)
\end{array}\right.
$$

Matrix elements are calculated from left to right and from bottom to top. The algorithm adds the distance value $\delta$ of the elements in that position of each series. The elements receive the lowest value from the previous adjacent elements to the left, down and diagonal. Once the matrix is completely filled, the last element at bottom right gives the value of the best alignment of the two time series.

DTW distance has been the subject of studies for analysis of SITS. Some researches, for example, used DTW as a tool to treat problems related to comparing time series of different sizes and irregular samples containing cloud cover (PETITJEAN et al., 2011; PETITJEAN et al., 2012). Another study presented a weighted version of DTW for land cover and land use classification (MAUS et al., 2016).

\section{Methodology}

The proposed spatio-temporal segmentation by region growing is diagrammed in Figure 3. The algorithm can be expressed by the following steps:

a) Select a sequence of images as input data.

b) Set similarity threshold.

c) Determine the seed set.

d) Compute the DTW distance between the time series of the seeds and their neighbors. If the absolute difference between the DTW value of the time series of the seed and the time series of the neighbor is less than the similarity threshold, the neighbor is considered similar and it is added to the region. 
e) Continue examining all the neighbors until no similar neighbor is found. Label the obtained segmented as a complete region.

f) Observe the next unlabeled seed and repeat the process until all the seeds or pixels are labelled in a region.

Figure 3 - Flowchart of the proposed methodology.

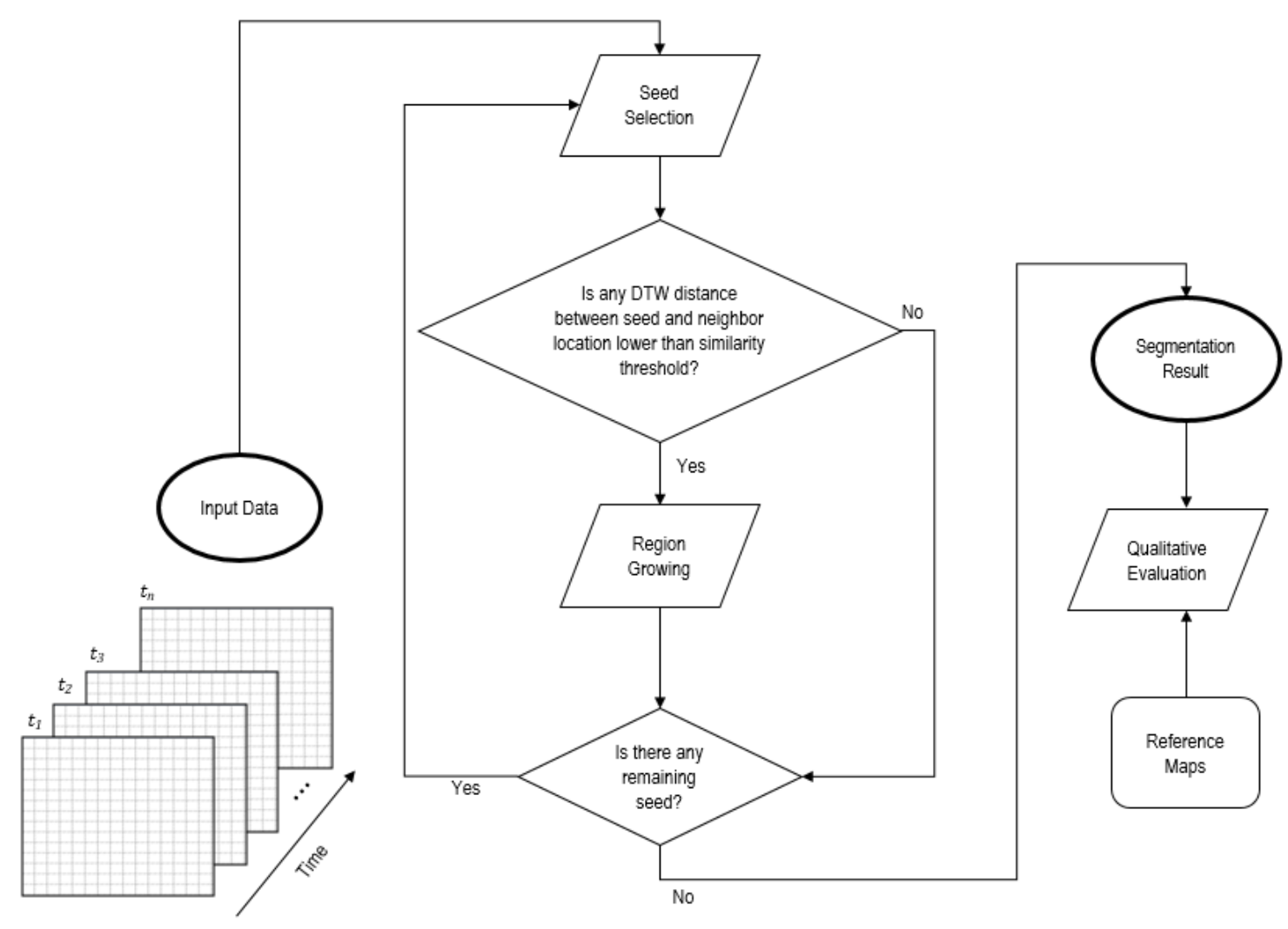

Source: Prepared by the authors

The core of our methodology is using DTW distance as the homogeneity criterion for growing regions in the study cases. These time series were used in DTW calculation between the seeds and its neighboring pixels. The segmentation algorithm was written using $\mathrm{R}$ language.

For the acceptance or rejection of a given threshold in a remote sensing image segmentation result, the resulting segments were compared with a remote sensing image at the same location of the scene in the end of the time series. The seed set, processing order and location of the seeds were set 
randomly by the algorithm. The segmentation result can also be visually compared with a reference map, previously set by photo-interpretation.

\section{Results and Discussion}

Our technique is used to evaluate two central-western areas in Brazil. The first test is conducted using NDVI MODIS scenes, with spatial resolution of $250 \mathrm{~m}$. The study area is located in the state of Mato Grosso (MT) and covers $250,000 \mathrm{~km}^{2}$, as illustrated in Figure 4. We use 92 NDVI scenes between January 2010 and December 2013, with temporal resolution of 16 days. The NDVI produced by MODIS images is retrieved from atmospherecorrected bidirectional surface reflectance. All images have a dimension of $2000 \times 2000$ pixels.

This test aims to illustrate the method utility for large areas. The area contains regions of large croplands and native vegetation areas. Since the spatial resolution of the images is low, the expected segmentation output includes large segmented areas with similar geo-objects presenting homogeneity over time. For the segmentation result presented in Figure 5, the similarity threshold was set to 0.05 . The similarity threshold is defined empirically, based on visual inspection of the results. The processing time was approximately 4 hours. 
Figure 4 - Study area for the first test. Landsat-8 (R4G3B2) imagery of the study area.

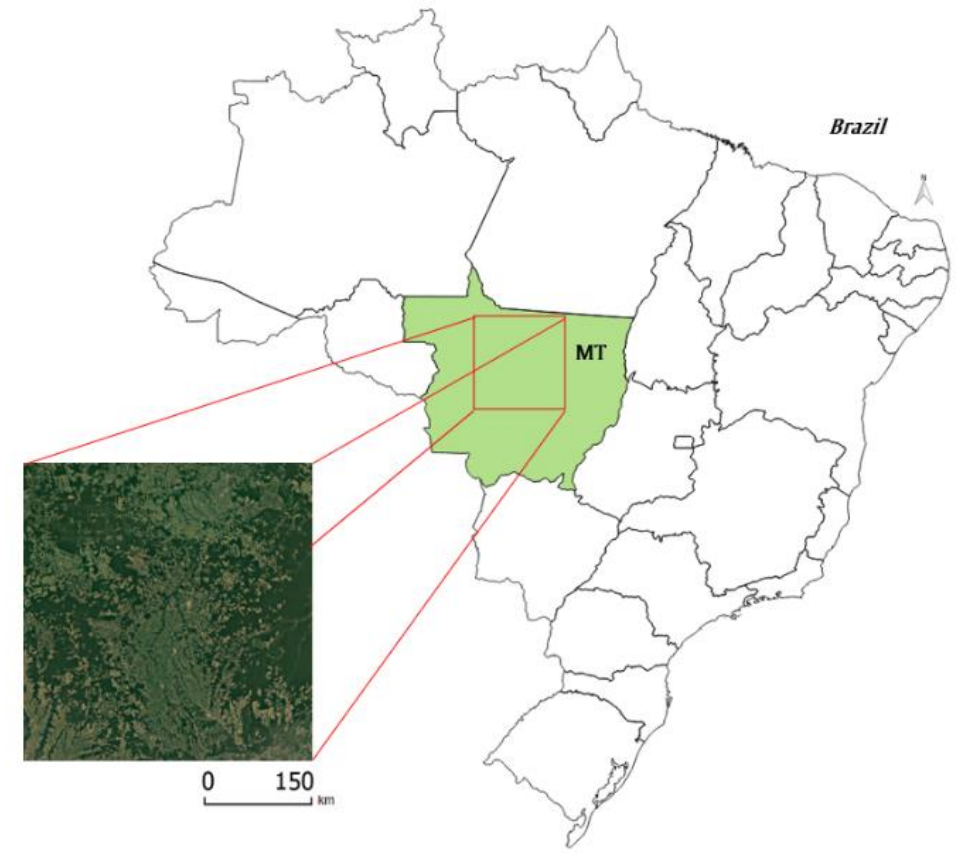

Source: Prepared by the authors.

Figure 5 - Segmentation output (red outlines) for the first test. The segments are superimposed on a Landsat-8 image (R4G3B2). The zoomed area shows that the algorithm distinguished native vegetation, croplands and urban areas.

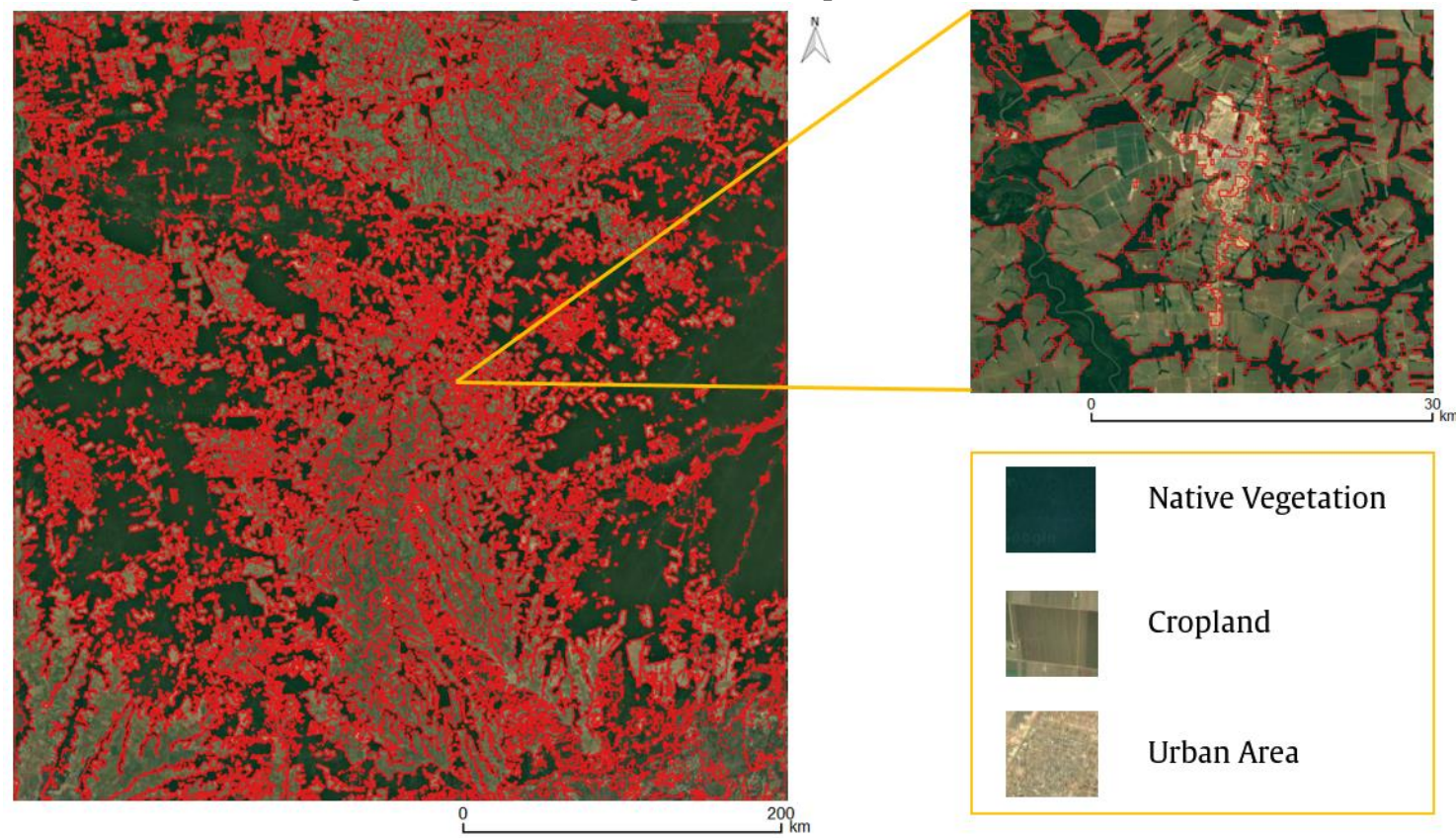

Source: Prepared by the authors.

Evaluating the segmentation result is difficult because there is no standard assessment techniques (EECKHAUT et al., 2012). For this test, we compared the segmentation result to a Landsat-8 image, evaluating the

Rev. Bras. de Cartografia, vol. 70, Special Issue "XIX Brazilian Syposium on

GeoInformatics", 2018. pp. 1779 - 1801. 
output based on photointerpretation of the satellite image. As shown in Figure 5, the segmentation distinguished regions corresponding to native vegetation, croplands and urban areas. Visually, the image objects represented similar-sized groups of geo-objects, such as trees, residential areas and agricultural fields.

In the second test, the study area covers a central area in the state of Goiás, located in Santo Antônio de Goiás City, illustrated in Figure 6. A sequence of 44 images obtained from NDVI Landsat-8 OLI between November 12, 2014 and September 30, 2016 are used, with temporal resolution of 16 days. All images have a dimension of $189 \times 161$ pixels, with spatial resolution of $30 \mathrm{~m}$.

Figure 6 - Study area for the second test using Landsat-8 OLI scenes. The yellow outlines are polygons provided by EMBRAPA. The labeled polygons (A1, A2, A3, A4, P1, P2, P3, P4, $\mathrm{P} 5$ and F1) were used as ground truth.

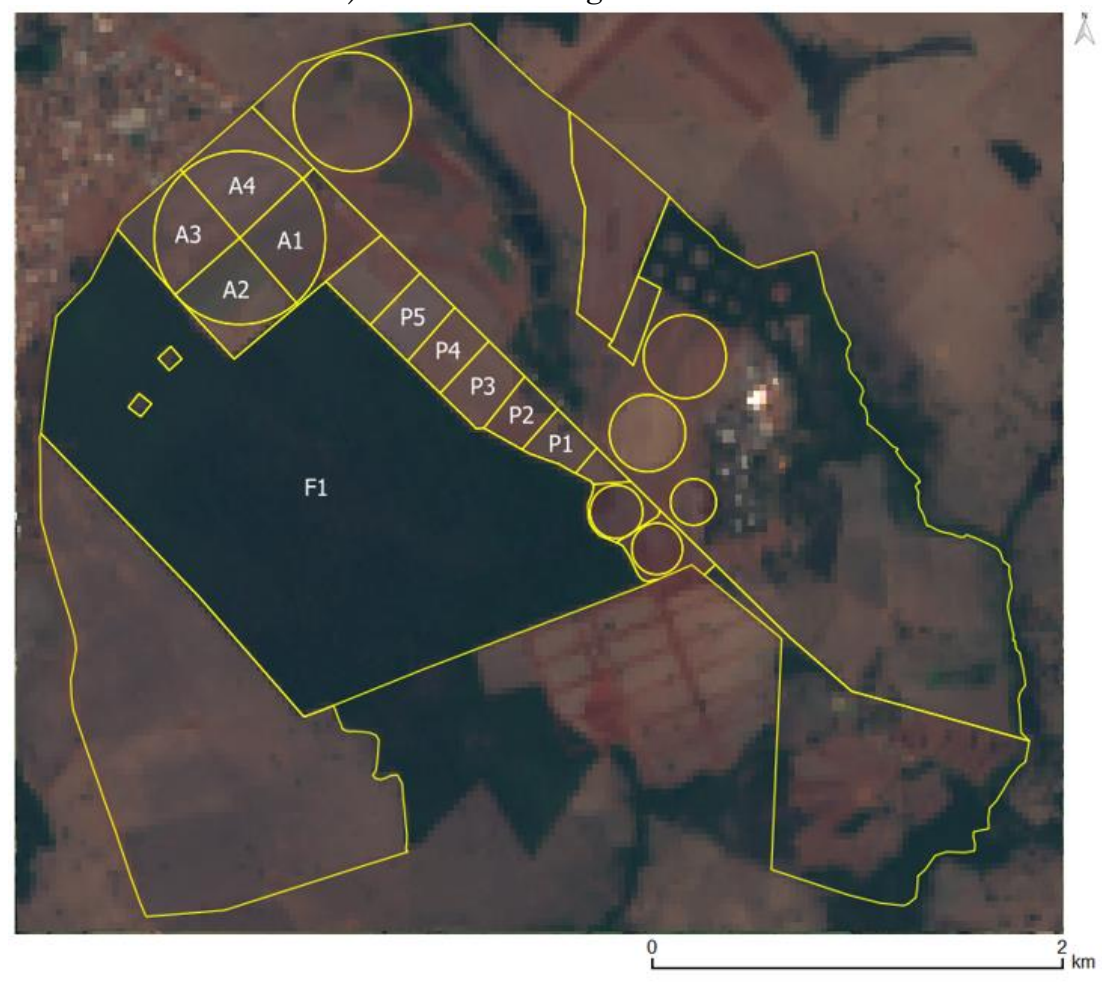

Source: Prepared by the authors.

In this test, we use 10 reference polygons as ground truth provided by Brazilian Agricultural Research Corporation (EMBRAPA) (BRAZIL, 2011). 
This subset of 10 polygons were chosen because they were regions with homogeneous properties in the described period, also according to information provided by EMBRAPA (see Table 1). The similarity threshold was chosen so that the agricultural, pasture and forest areas could be separated from the other neighboring targets.

Also, in this experiment, the similarity threshold was defined empirically, as 0.045 . The processing time was 183 seconds. The segmentation result is shown in Figure 7. Visually, the proposed method was able to create similar-shaped segments compared to the reference polygons. To evaluate this result, the segmented regions were visually compared to reference polygons.

Table 1 - Land use description of each labeled polygon for each harvest/winter.

\begin{tabular}{c|c|c|c|c}
\hline Label & $\begin{array}{c}\text { Harvest } \\
(2014 / 2015)\end{array}$ & $\begin{array}{c}\text { Winter } \\
(2015)\end{array}$ & $\begin{array}{c}\text { Harvest } \\
(2015 / 2016)\end{array}$ & $\begin{array}{c}\text { Winter } \\
(2016)\end{array}$ \\
\hline P1 & pasture & pasture & pasture & pasture \\
\hline P2 & pasture & pasture & pasture & pasture \\
\hline P3 & soybean & fallow & rice & fallow \\
\hline P4 & rice & fallow & $\begin{array}{c}\text { maize }+ \\
\text { brachiaria }\end{array}$ & pasture \\
\hline P5 & pasture & pasture & soybean & fallow \\
\hline A1 & maize + & pasture & soybean & fallow \\
brachiaria & rice & fallow & $\begin{array}{c}\text { maize }+ \\
\text { brachiaria }\end{array}$ & fallow \\
\hline A3 & soybean & fallow & rice & pasture \\
\hline A4 & pasture & pasture & soybean & fallow \\
\hline F1 & forest & forest & forest & forest \\
\hline
\end{tabular}

Visually, the segmented polygons represented regions of similar size to the reference polygons P3, P4, P5, and F1. However, the segmented polygon that corresponds to $\mathrm{P} 1$ presented similar behavior to its neighboring polygon during the two analyzed years. The algorithm considered the two polygons as a single area with homogeneous properties in the observed period. A similar 
case occurred with polygons A1 and A4. As can be seen in Table 1, the two areas have the same type of land use, differing only in the harvest (2014/2015). The method considered the two areas as a single region. However, the references A2 and A3 were the ones that most diverged from the algorithm result, since each one of them were separated into two distinct regions.

Figure 7 - Landsat-8 image (R4G3B2) (left) superimposed with segmentation results (blue outlines). Zoomed area (right) containing the labeled reference polygons (yellow outlines) and the segmented polygons (blue outlines).
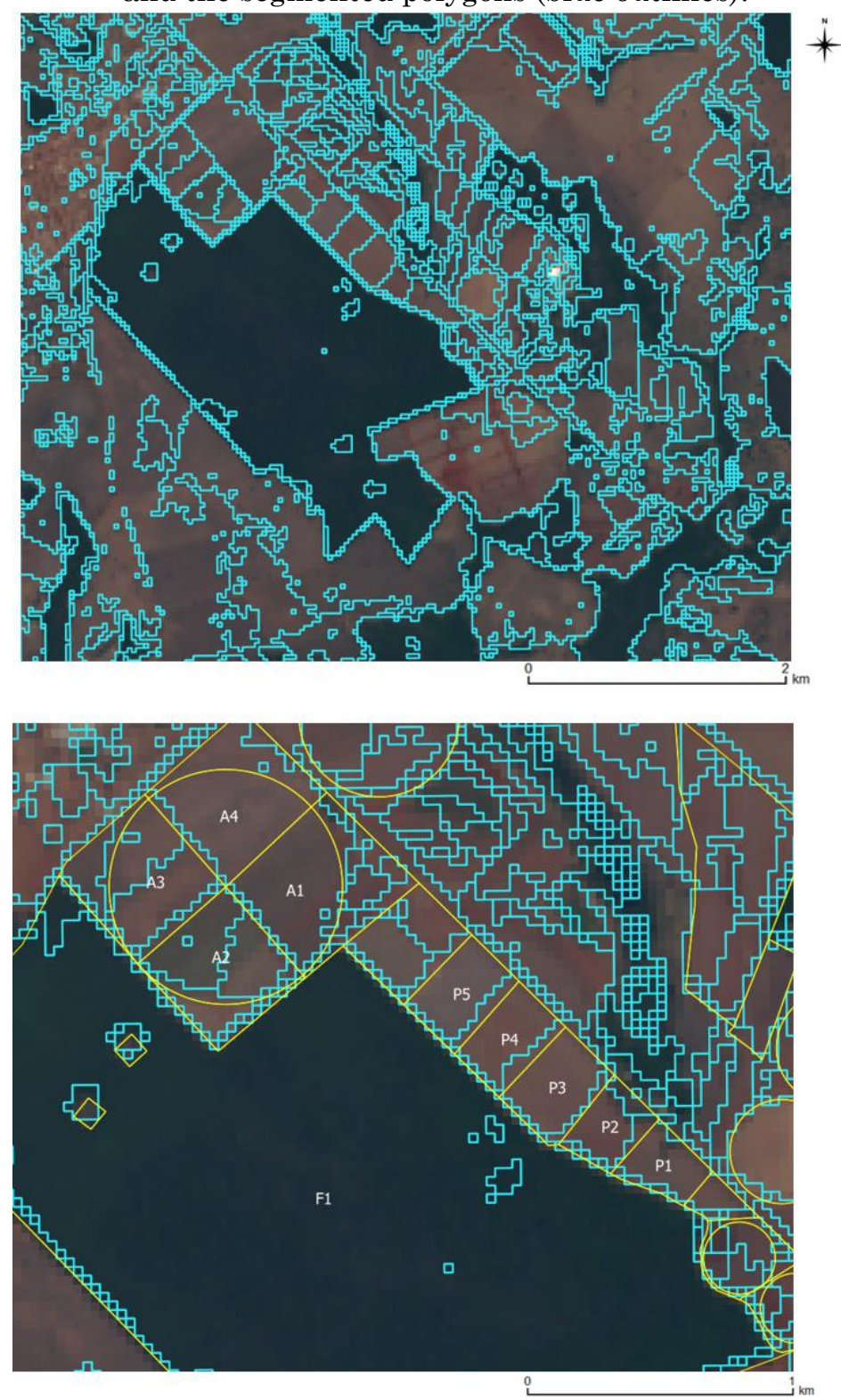

Source: Prepared by the authors.

Rev. Bras. de Cartografia, vol. 70, Special Issue "XIX Brazilian Syposium on

GeoInformatics”, 2018. pp. 1779 - 1801. 
In order to compare the efficiency of DTW distance in handling noisy data, the proposed method is compared with segmentation results that used other metrics as criterion of homogeneity. The segmentation results are generated using Manhattan (Figure 8) and Euclidean distances (Figure 9) instead of applying DTW as homogeneity criterion, using the same seed set. The similarity threshold was reached using the same seed set and processing order of the seed in all tests.

Figure 8 - Landsat-8 imagery compared with segmentation results using Manhattan distance as homogeneity criterion.

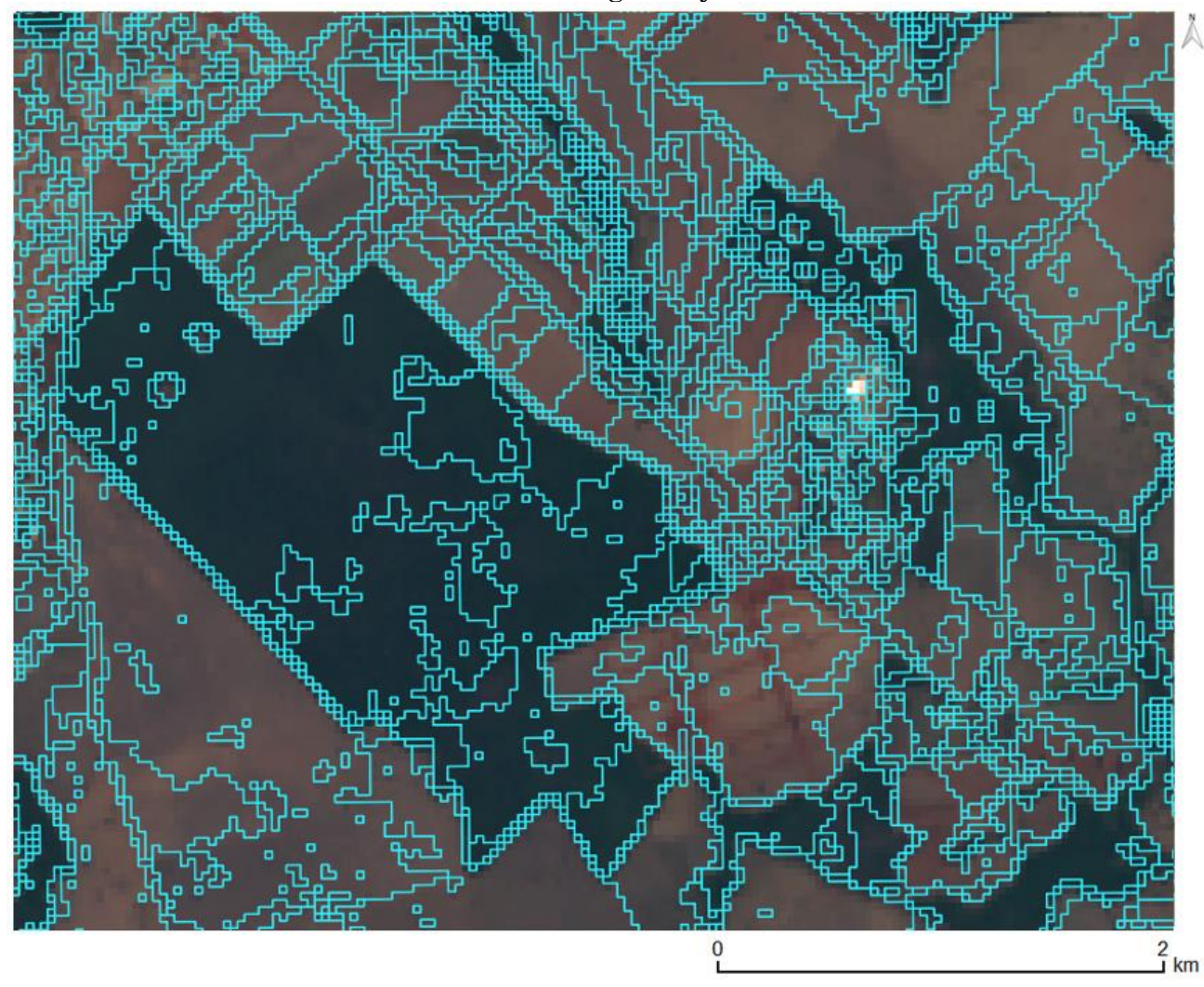

Source: Prepared by the authors.

Rev. Bras. de Cartografia, vol. 70, Special Issue "XIX Brazilian Syposium on

GeoInformatics", 2018. pp. $1779-1801$. 
Figure 9 - Landsat-8 imagery compared with segmentation results using Euclidean distance as homogeneity criterion.

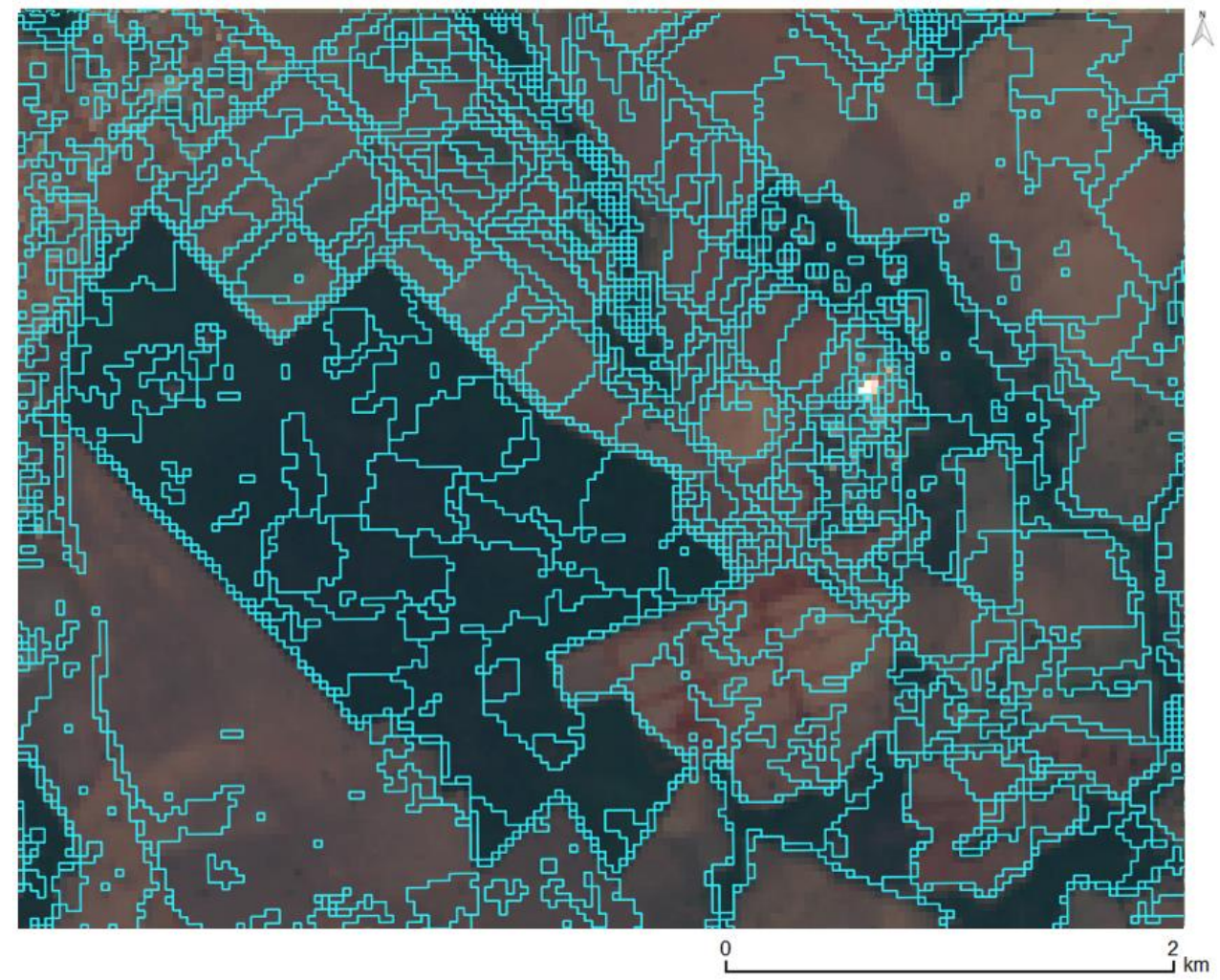

Source: Prepared by the authors.

The similarity thresholds are also defined empirically, in this case set to 2.4 and 0.6 for Manhattan and Euclidean results, respectively. Visually, the proposed method (using DTW) is able to create better segments compared to the results using Manhattan and Euclidean distances. It can be seen clearly, especially the segmented polygons that corresponds to F1, that the segmentation using other distances over-segmented the labeled references in comparison with the proposed method. Most of sliver polygons are derived from cloud cover presence in Landsat-8 images, which demonstrates the effectiveness of the DTW distance in treating temporal and noisy data in comparison with the other distances.

Both tests are encouraging and demonstrate the potential of the proposed spatio-temporal segmentation in dealing with time series generated by images of different sensors and spatial resolutions. However, one factor 
that reduces the quality of the segments is the noise in the time series derived from cloud cover, especially in the second test with Landsat-8 OLI scenes.

Once the proposed method is based on region growing technique, the algorithm contains some disadvantages. Different seed sets, for example, cause different results in segmentation. In addition, DTW calculation demands a high computational cost.

\section{Conclusion}

In this paper, we proposed a multitemporal methodology for segmentation. The use of efficient segmentation algorithms represents an important role because they provide homogeneous regions in space-time and hence simplify the data set. In addition, the spatio-temporal segmentation brings a new way of interpreting data by means of analyzing contiguous regions in time. In order to illustrate the potential of the method, we presented two tests on NDVI time series derived from MODIS and Landsat8 OLI sensors. We compared the segments generated by the proposed algorithm based on photo-interpretation, observing similarities between segmentation and reference.

The DTW computation and the use of the temporal dimension increases the complexity of processing compared with the segmentation of satellite images which considers only a single date. Further analysis is needed to apply this approach in regions with higher temporal resolutions and to test different indices and spatial resolutions of Landsat-like image time series. In addition, quantitative evaluation measures will be investigated to analyze the segmentation outputs. 


\section{Acknowledgments}

The authors would like to acknowledge the financial support of CAPES, FAPESP e-sensing program (grant 2014/08398-6) and CAPES/COFECUB Programme for the GeoABC Project (n. 845/15) as well as information support of Embrapa National Center for Research on Rice and Beans (CNPAF) and Embrapa LabEx Europe.

\section{References}

ADAMS, R.; BISCHOF, L. Seeded region growing. Pattern Analysis and Machine Intelligence, IEEE Transactions on, IEEE, v. 16, n. 6, 1994, pp. 641-647.

BINS, L. S.; FONSECA, L. M. G.; ERTHAL, G. J.; II, F. M. Satellite imagery segmentation: a region growing approach. Simpósio Brasileiro de Sensoriamento Remoto, Imagem Multimidia, São Paulo. Proceedings, CD Salvador, Bahia, Brazil, v. 8, n. 1996, pp. 677-680.

BLASCHKE, T. Towards a framework for change detection based on image objects.

Göttinger Geographische Abhandlungen, v. 113, 2005, pp. 1-9.

BLASCHKE, T. Object based image analysis for remote sensing. ISPRS Journal of Photogrammetry and Remote Sensing, Elsevier, v. 65, n. 1, 2010, pp. 216.

BONTEMPS, S.; BOGAERT, P.; TITEUX, N.; DEFOURNY, P. An object-based change detection method accounting for temporal dependences in time series with medium to coarse spatial resolution. Remote Sensing of Environment, Elsevier, v. 112, n. 6, 2008, pp. 3181-3191.

BORIAH, S. Time series change detection: algorithms for land cover change. Thesis (Doctorate) - University of Minnesota, 2010. 160 p.

BOULILA, W.; FARAH, I. R.; ETTABAA, K. S.; SOLAIMAN, B.; GHÉZALA, H. B. A data mining based approach to predict spatiotemporal changes in satellite images. International Journal of Applied Earth Observation and Geoinformation, Elsevier, v. 13, n. 3, 2011, pp. 386-395. 
BRAZIL. Sectoral plan for climate mitigation and adaptation. Ministry of agriculture, Livestock and Food Supply. Brasilia, 2011.

BRUZZONE, L.; SMITS, P. C.; TILTON, J. C. Foreword special issue on analysis of multitemporal remote sensing images. Geoscience and Remote Sensing, IEEE Transactions on, IEEE, v. 41, n. 11, 2003, pp. 2419-2422.

COHEN, W. B.; GOWARD, S. N. Landsat's Role in Ecological Applications of Remote Sensing. BioScience, v. 54, n. 6, 2004, pp. 535-545.

COSTA, W. S.; FONSECA, L. M. G.; KORTING, T. S.; SIMÕES, M. G.; BENDINI, H. N.; SOUZA, R. C. M. Segmentation of optical remote sensing images for detecting homogeneous regions in space and time. In: XVIII Brazilian Symposium on GeoInformatics (GeoInfo). Proceedings. Salvador, National Institute for Space Research, 2017, pp. 40-51.

CHU, S.; KEOGH, E.; HART, D.; PAZZANI, M. Iterative deepening dynamic time warping for time series. In: Proceedings of the 2002 SIAM International Conference on Data Mining. Philadelphia, PA: Society for Industrial and Applied Mathematics, 2002, pp. 195-212.

DESCLÉE, B.; BOGAERT, P.; DEFOURNY, P. Forest change detection by statistical object-based method. Remote Sensing of Environment, Elsevier, v. 102, n. 1, 2006, pp. 1-11.

DEY, V.; ZHANG, Y.; ZHONG, M. A review on image segmentation techniques with remote sensing perspective. ISPRS Journal of Photogrammetry and Remote Sensing, ISPRS, Viena, Austria, XXXVIII, 2010, pp. 31-42.

DRĂGUT,, L.; CSILLIK, O.; EISANK, C.; TIEDE, D. Automated parameterisation for multi-scale image segmentation on multiple layers. ISPRS Journal of Photogrammetry and Remote Sensing, Elsevier, v. 88, 2014, pp. 119-127.

DRĂGUȚ, L.; TIEDE, D.; LEVICK, S. R. ESP: a tool to estimate scale parameter for multiresolution image segmentation of remotely sensed data. International Journal of Geographical Information Science, Taylor \& Francis, v. 24, n. 6, 2010, pp. 859-871.

DURO, D.; FRANKLIN, S.; DUBÉ, M. Hybrid object-based change detection and hierarchical image segmentation for thematic map updating. Photogrammetric Engineering \& Remote Sensing, American Society for Photogrammetry and Remote Sensing, v. 79, n. 3, 2013, pp. 259-268. 
EECKHAUT, M. V. D.; KERLE, N.; POESEN, J.; HERVÁS, J. Object-oriented identification of forested landslides with derivatives of single pulse lidar data. Geomorphology, v. 173-174, 2012, pp. 30-42.

FREITAS, R. D.; ARAI, E.; ADAMI, M.; FERREIRA, A. S.; SATO, F. Y.; SHIMABUKURO, Y. E.; ROSA, R. R.; ANDERSON, L. O.; RUDORFF, B. F. T. Virtual laboratory of remote sensing time series: visualization of MODIS EVI2 data set over South America. Journal of Computational Interdisciplinary Sciences, v. 2, n. 1, 2011, pp. 57-68.

GÓMEZ, C.; WHITE, J. C.; WULDER, M. A. Characterizing the state and processes of change in a dynamic forest environment using hierarchical spatio-temporal segmentation. Remote Sensing of Environment, Elsevier, v. 115, n. 7, 2011. pp. 1665-1679.

HARALICK, R. M.; SHAPIRO, L. G. Image segmentation techniques. In: Technical Symposium East. Arlington, VA: International Society for Optics and Photonics, 1985.

HUETE, A.; DIDAN, K.; MIURA, T.; RODRIGUEZ, E. P.; GAO, X.; FERREIRA, L. G. Overview of the radiometric and biophysical performance of the modis vegetation indices. Remote Sensing of Environment, Elsevier, v. 83, n. 1, 2002, pp. 195-213.

IM, J.; JENSEN, J.; TULLIS, J. Object-based change detection using correlation image analysis and image segmentation. International Journal of Remote Sensing, Taylor \& Francis, v. 29, n. 2, 2008, pp. 399-423.

JIANG, Z.; HUETE, A. R.; DIDAN, K.; MIURA, T. Development of a two-band enhanced vegetation index without a blue band. Remote Sensing of Environment, Elsevier, v. 112, n. 10, 2008, pp. 3833-3845.

JUSTICE, C.; TOWNSHEND, J.; VERMOTE, E.; MASUOKA, E.; WOLFE, R.; SALEOUS, N.; ROY, D.; MORISETTE, J. An overview of MODIS land data processing and product status. Remote sensing of Environment, Elsevier, v. 83 , n. 1, 2002, pp. 3-15.

LAMBIN, E. F.; LINDERMAN, M. Time series of remote sensing data for land change science. Geoscience and Remote Sensing, IEEE Transactions on, IEEE, v. 44, n. 7, 2006, pp. 1926-1928. 
MAUS, V.; CAMARA, G.; CARTAXO, R.; RAMOS, F. M.; SANCHEZ, A.; RIBEIRO, G. Q. Open boundary dynamic time warping for satellite image time series classification. In: 2015 IEEE International Geoscience and Remote Sensing Symposium (IGARSS). IEEE, 2015, pp. 3349-3352.

NIEMEYER, I.; MARPU, P.; NUSSBAUM, S. Change detection using object features. In: BLASCHKE, T.; LANG, S.; HAY, G. (Ed.). Object-Based Image Analysis. Springer Berlin Heidelberg, (Lecture Notes in Geoinformation and Cartography), 2008, pp. 185-201.

OLIVEIRA, J. C. D. Índice para avaliação de segmentação (IAVAS): uma aplicação em agricultura. Dissertação (Mestrado - Instituto Nacional de Pesquisas Espaciais, 160 p. São José dos Campos, 2002.

PAPE, A. D.; FRANKLIN, S. E. MODIS-based change detection for Grizzly Bear habitat mapping in Alberta. Photogrammetric Engineering \& Remote Sensing, American Society for Photogrammetry and Remote Sensing, v. 74, n. 8, 2008, pp. 973-985.

PETITJEAN, F.; INGLADA, J.; GANÇARSKI, P. Clustering of satellite image time series under time warping. In: IEEE. Analysis of Multi-temporal Remote Sensing Images (Multi-Temp), 2011 6th International Workshop on the. Trento, Italy, 2011.

PETITJEAN, F.; INGLADA, J.; GANÇARSKI, P. Satellite image time series analysis under time warping. Geoscience and Remote Sensing, IEEE Transactions on, IEEE, v. 50, n. 8, 2012, pp. 3081-3095.

SAKOE, H.; CHIBA, S. A dynamic programming approach to continuous speech recognition. In: Proceedings of the seventh international congress on acoustics. Budapest: Akademiai Kiado, v. 3, 1971, pp. 65-69.

SAKOE, H.; CHIBA, S. Dynamic programming algorithm optimization for spoken word recognition. In: Acoustics, Speech and Signal Processing, IEEE Transactions on. New York, NY: IEEE, v. 26, n. 1, 1928, pp. 43-49.

SCHIEWE, J. Segmentation of high-resolution remotely sensed data-concepts, applications and problems. International Archives of Photogrammetry Remote Sensing and Spatial Information Sciences, Natural Resources Canada, v. 34, n. 4, 2002, pp. 380-385. 
THOMPSON, J. A.; LEES, B. G. Applying object-based segmentation in the temporal domain to characterise snow seasonality. ISPRS Journal of Photogrammetry and Remote Sensing, Elsevier, v. 97, 2014, pp. 98-110.

TUCKER, C. J. Red and photographic infrared linear combinations for monitoring vegetation. Remote sensing of Environment, Elsevier, v. 8, n. 2, 1979, pp. $127-150$.

TUCKER, C. J.; PINZON, J. E.; BROWN, M. E.; SLAYBACK, D. A.; PAK, E. W.; MAHONEY, R.; VERMOTE, E. F.; SALEOUS, N. E. An extended AVHRR 8$\mathrm{km}$ NDVI dataset compatible with MODIS and SPOT vegetation NDVI data. International Journal of Remote Sensing, Taylor \& Francis, v. 26, n. 20, 2005, pp. 4485-4498. 